\title{
Hydrological alteration: the missing dimension of water in wastewater treatment plants. The case of the Manzanares River in Madrid (Spain)
}

\author{
Natalia Pérez-Andrés ${ }^{1}$, Carolina Martínez-Santamaría ${ }^{1}$, Fernando Magdaleno ${ }^{1}$, Roberto \\ Martínez-Romero², and José Fernández ${ }^{3}$ \\ ${ }^{1}$ Polytechnic University of Madrid \\ ${ }^{2}$ Scottish Environment Protection Agency \\ ${ }^{3}$ Polytechnic University of Madrid - Forest Engineering Technical College
}

June 24, 2021

\begin{abstract}
The effects of the discharge of wastewater treatment plants (WWTP) on the status of rivers have most commonly been focused on water quality. A very limited number of works have characterised the ability of treatment plants to modify flow patterns in the receiving rivers. This paper presents a methodology for the assessment of the hydrologic alteration caused by WWTP discharges, over a two-fold sequence. The first phase comprises the application of indicators derived from accessible data and informative of the capacity of treatment plants to produce significant flow alterations. The second phase, which may only be carried out when flow data in the receiving river is available, is based on the indicators of hydrologic alteration provided by the free software IAHRIS (6 indicators) and IHA ( 2 indicators), and on a new indicator proposed in this paper to obtain information of flow alteration at seasonal and monthly time scales. The procedure suggested in this work is applied to the Manzanares River (Central Spain), allowing the quantification of the flow alteration generated by the 12 WWTP which give service to Madrid city (3.8 million inhabitants): Large increases of annual water volumes (from $108 \mathrm{hm} 3$ to $410 \mathrm{hm} 3$ ); at a monthly scale (increase from $246 \%$ to $1516 \%$ ); variability in flow decreases in wet years by up to $47 \%$ and increases in dry years by up to $380 \%$; seasonal patterns is altered within an altered regime. Results of the analysis show: (i) the ability of the proposed methodology to characterise the modification of flow patterns due to WWTP discharges; (ii) the importance of assessing such changes when evaluating the environmental impact of treatment plants; (iii) the importance of designing preventive and mitigation measures which maintain the ecological integrity of river ecosystems in the receiving channels.
\end{abstract}

\section{Hosted file}

MAIN_TEXT_FILE.docx available at https://authorea.com/users/421618/articles/527567hydrological-alteration-the-missing-dimension-of-water-in-wastewater-treatment-plantsthe-case-of-the-manzanares-river-in-madrid-spain

\section{Hosted file}

Tables.docx available at https://authorea.com/users/421618/articles/527567-hydrologicalalteration-the-missing-dimension-of-water-in-wastewater-treatment-plants-the-case-ofthe-manzanares-river-in-madrid-spain 


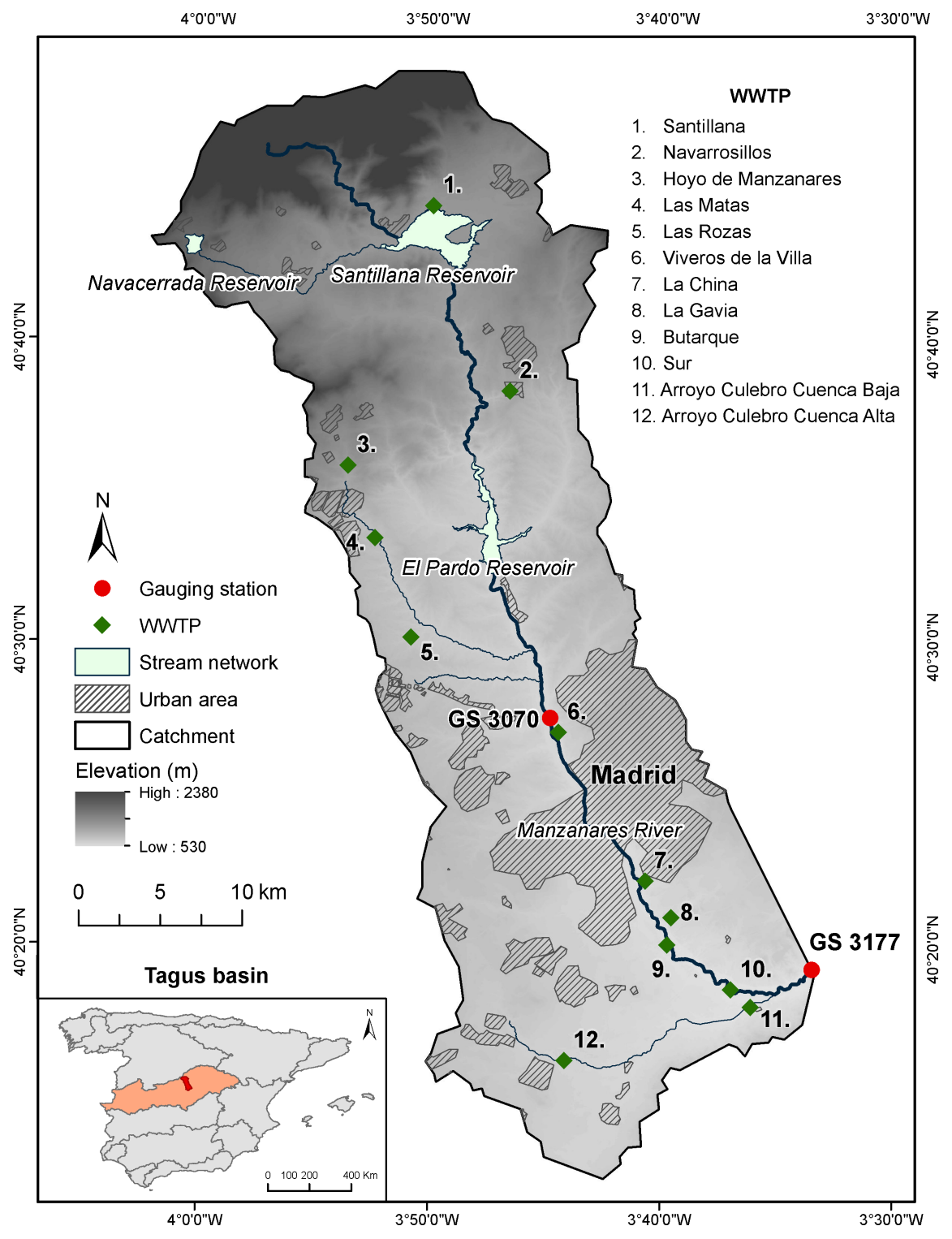

Annual water volumes $\left(\mathrm{hm}^{3}\right)$

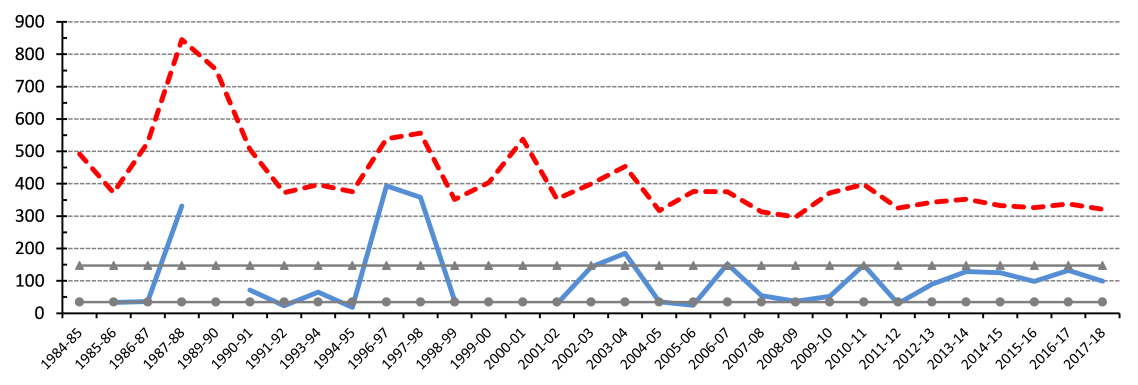



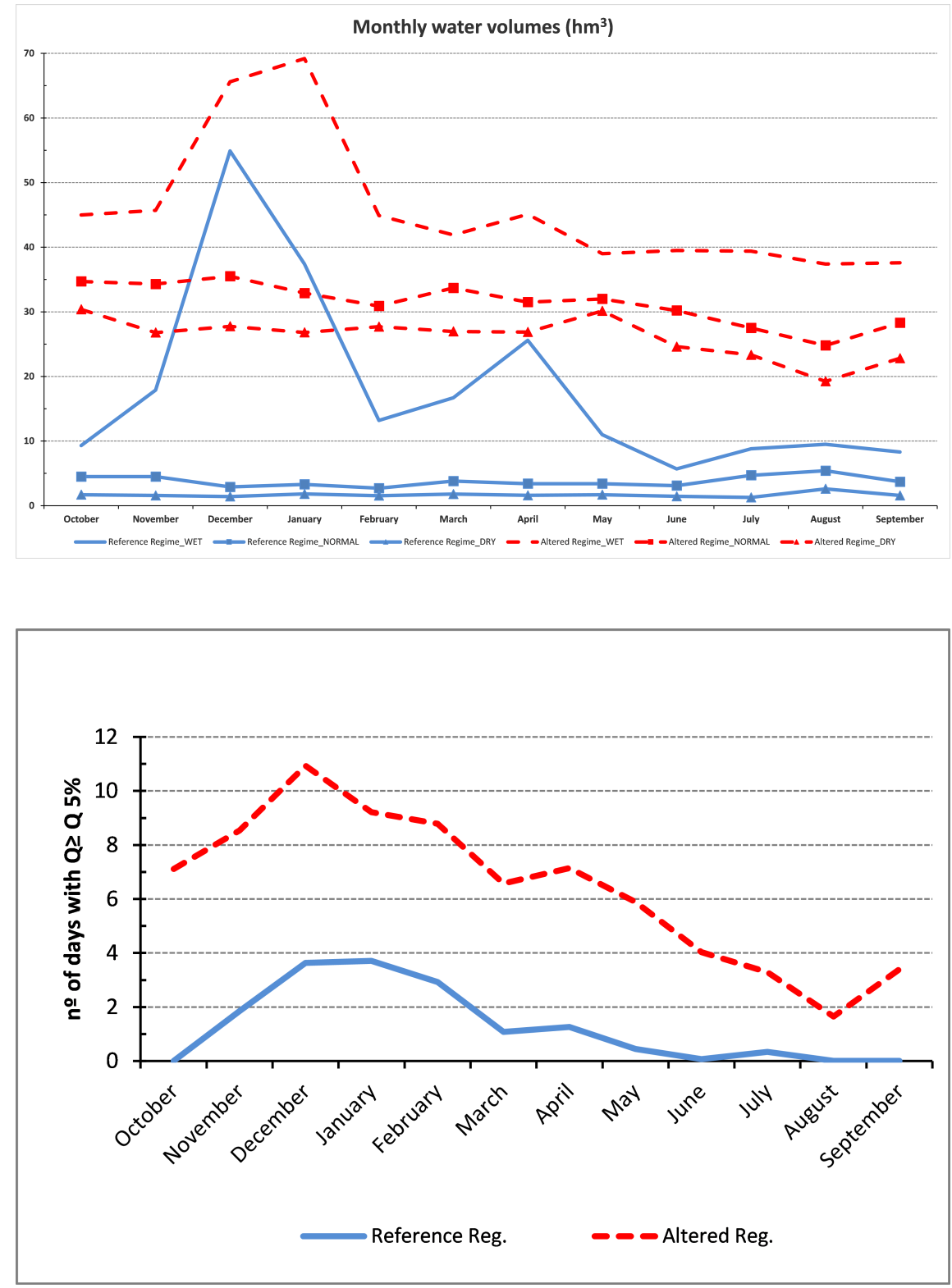

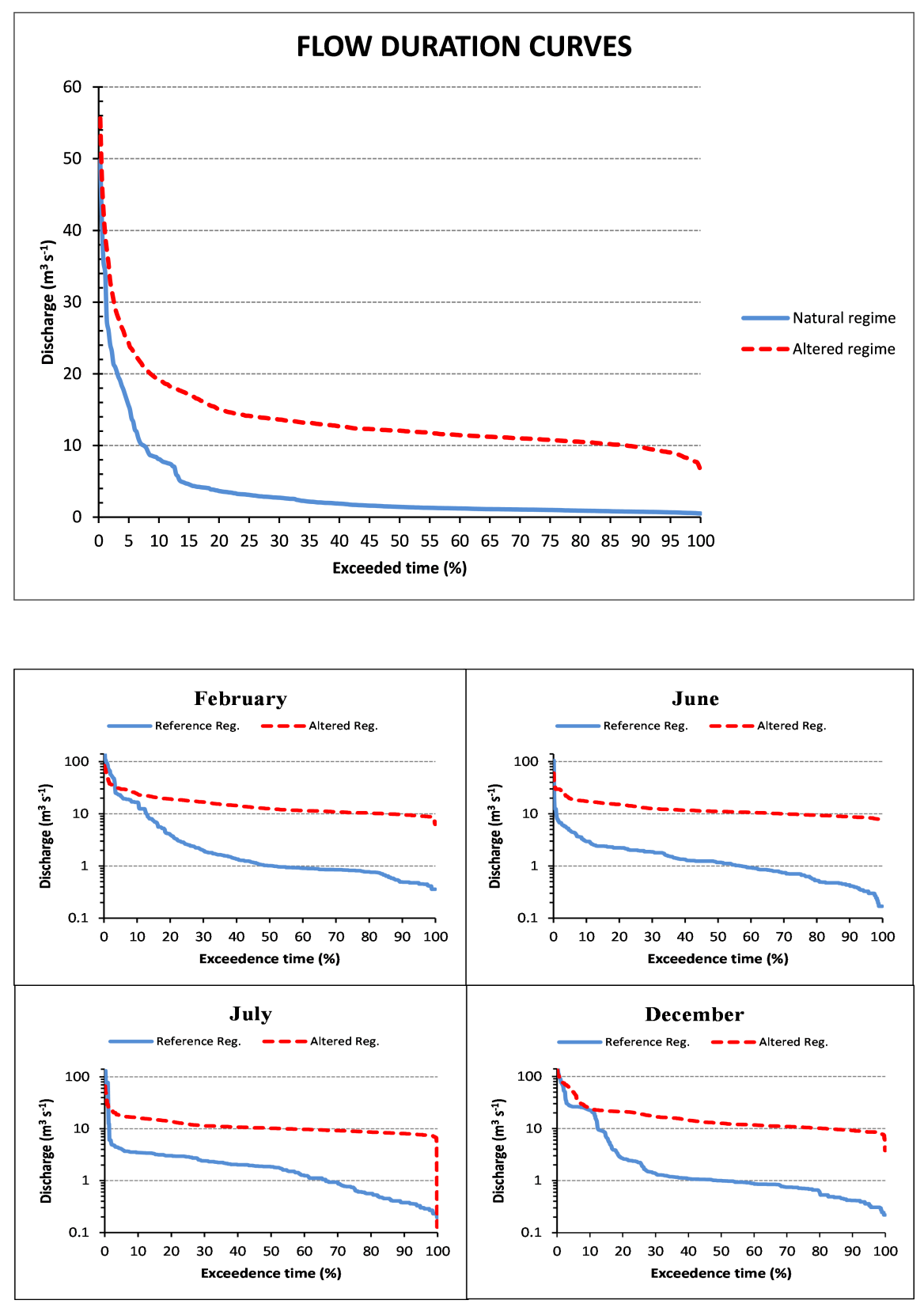


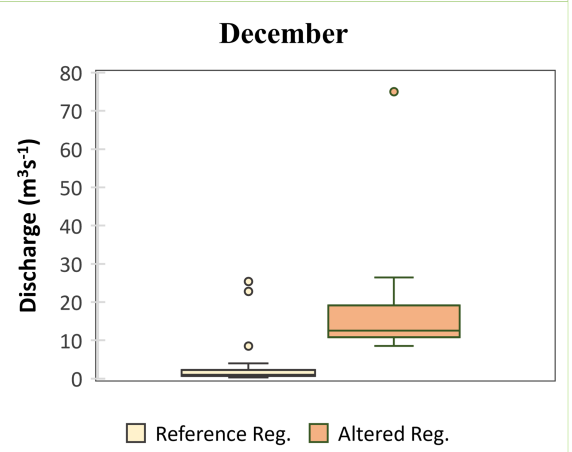

February
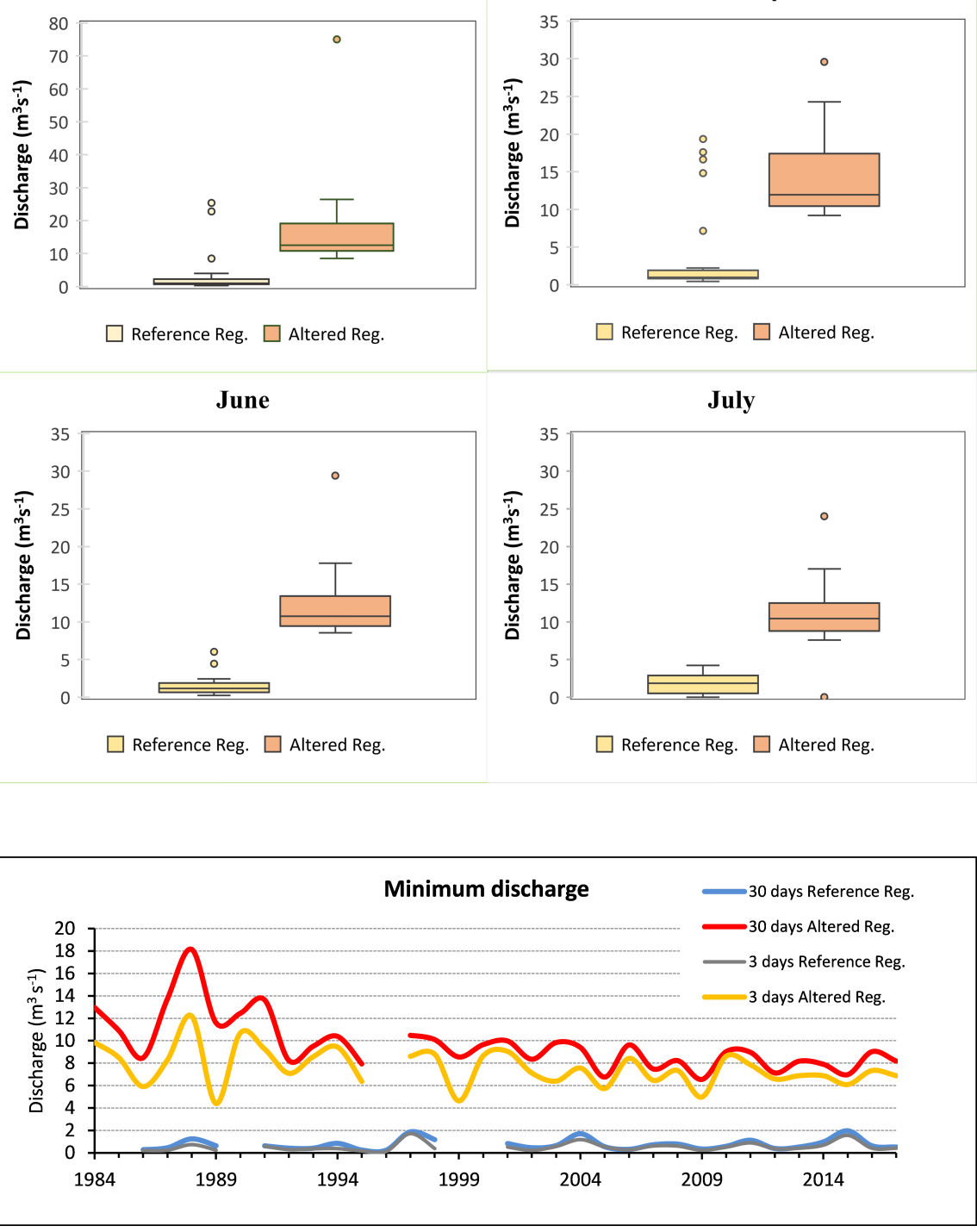